\title{
To publish or not to publish
}

To the Editor - Your January editorial ${ }^{1}$ touches on the issue of whether the heritable genome editing experiment resulting in the claimed birth of genome-edited twin girls Lulu and Nana (pseudonyms) should have been published - and more specifically whether excerpts of data from them should have been republished. On the basis of information in the public domain - slides presented by Jiankui He at the Second International Summit on Human Genome Editing $^{2}$ in Hong Kong in late November 2018 and excerpts of an unpublished manuscript authored by Jiankui He and colleagues disclosed ${ }^{3}$ in MIT Technology Review in early December 2019 - these experiments are widely considered both unscientific and unethical. This prompts two discrete questions: "Should unscientific research be published?" and "Should unethical research be published?"

My unequivocal answer to the first question is no.

I am a philosopher with a specialization in bioethics, not a scientist. I note, however, that eminent scientists who have commented on the available data agree that the experiment was unsafe and premature.

The science was not robust - the experiment was poorly designed and poorly executed - and thus it lacked scientific merit. If this be so, it follows that the work done by $\mathrm{He}$ is not worthy of publication for the simple reason that it does not contribute to generalizable knowledge.

What purpose would be served by publishing the complete manuscript other than satisfying the voyeuristic interests or impulses of some? The problems of mosaicism and off-target CRISPR activity in genome editing are already known. Indeed, to quote Kiran Musunuru, a scientist who has a copy of the full manuscript, "He's work was a graphic demonstration of attempted gene editing gone awry." ${ }^{4}$ Credible science journals are not in the business of publishing experiments that have gone awry.

The only persons who "need to know what happened to CRISPR twins Lulu and Nana" ${ }^{4}$ and who thus require access to the complete manuscript are the clinicianscientists directly involved in providing care for the genetically modified twins. They have a genuine need to know exactly what was done in creating these children so that they can provide care in the best interests of the children.

Having answered the first question in the negative, the second question, "Should unethical research be published?", is moot.

But what if, for the sake of argument, the first question had been answered in the affirmative? Then, the pivotal question would be, "Should scientifically sound, unethical research be published?" My answer to this question, which is about good science and offensive ethics, is somewhat more tentative: perhaps.

In making the point that He's research should not be published because it is unethical, some have compared his experiment to research conducted under the Nazi dictatorship. In that case, it has been argued that data obtained from experiments involving concentration camp prisoners should not be disseminated or cited not only because of "critical shortcomings in scientific content and credibility" ${ }^{\text {, but also }}$ because of ethical failings on the part of those conducting the research (for example, data falsification) and because of the moral horrors of the Holocaust. There are, however, some who believe otherwise.

Some years ago, Benjamin Freedman, a Jewish bioethics scholar, persuasively argued that Nazi research that met the standards of scientific validity and generated useful data should be used "to aid patients and to advance science in the interest of humankind" 6 - otherwise, the Jews who were murdered in the experiments would have died in vain. Using this reasoning, if He's research had scientific merit and could advance science in pursuit of the common good, then it would be worth engaging in an ethical debate as to whether his research should be published.

As mentioned above, however, He's research is bad science. As such, it does not warrant publication on scientific grounds.

Françoise Baylis (D)

Dalhousie University, Halifax, Nova Scotia, Canada. e-mail:francoise.baylis@dal.ca

Published online: 13 February 2020 https://doi.org/10.1038/s41587-020-0435-1

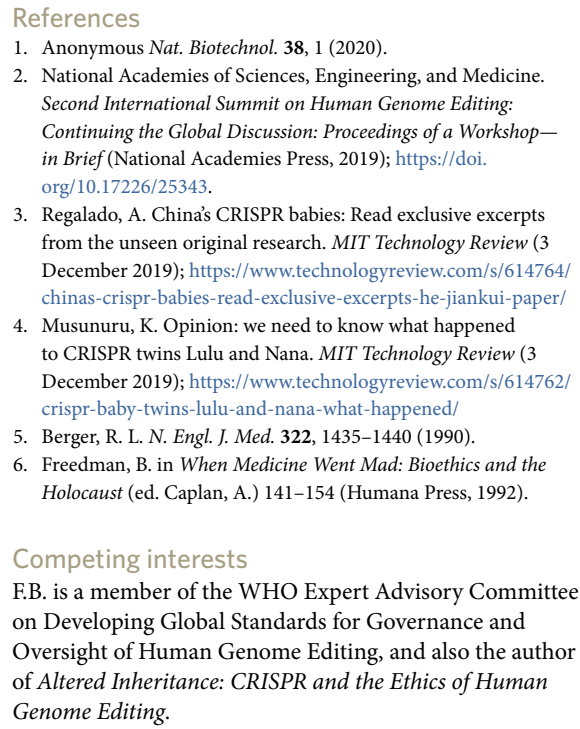

